REVIEW PAPER

\title{
INDIAN SPICES BOOST THE IMMUNE SYSTEM AGAINST COVID-19
}

\author{
ASITA ELENGOE \\ Department of Biotechnology, Faculty of Science, Lincoln University College, 47301 Petaling \\ Jaya, Selangor, Malaysia \\ asitaelengoe@yahoo.com
}

Received on 7 October 2020

Revised on 13 November 2020

\begin{abstract}
Since $12^{\text {th }}$ December 2019, the epidemic outbreak of an unknown acute respiratory tract infection has emerged in Wuhan City, China. The World Health Organization (WHO) discovered that this outbreak was caused by the 2019 novel coronavirus (2019-nCoV) or the extreme acute respiratory coronavirus 2 syndrome (SARSCoV-2). No vaccine or no specific anti-viral treatment against COVID-19 has been made available so far. Therefore, COVID-19 can be prevented by enhancing the body's immune system and fighting off the symptoms. Nuclear factor kappalight-chain-enhancer of activated $B$ cells $(N F-\kappa B)$ is one of the essential transcription factors in humans which are responsible for the regulation of immune cell, synthesis of pro-inflammatory cytokines and gene expression of inflammatory molecules and reactive oxygen species (ROS). Phytochemicals derived from Indian spices (turmeric, garlic, ginger, etc.) can modulate the gene expression in the NF- $\mathrm{KB}$ pathway. In the midst of pandemic COVID-19, adding spices to food (eg. 'Rasam') can boost up the body's immune system. Indian spices are emerging as potential agents for the prevention of COVID-19.
\end{abstract}

Keywords: SARS-CoV-2, COVID-19, NF-кB, Indian spices, 'Rasam'

\section{Introduction}

The novel 2019 coronavirus (2019-nCoV) or the severe acute respiratory syndrome coronavirus 2 (SARS-CoV-2) is a major threat to public health. It has been spreading rapidly from Huanan South China Seafood Market at Wuhan City, Hubei Province, China to other countries such as Thailand, South Korea, Japan, Taiwan, Singapore, Italy, Iran, Canada, France, Vietnam and the United States of America (USA) since $12^{\text {th }}$ December 2019 (Guo et al., 2020). The Government of China reported to World Health Organization (WHO) about the cluster cases of unknown pneumonia in Wuhan City on $31^{\text {st }}$ December 2019 (World Health Organization, 2020a). The Chinese

https://doi.org/10.35219/foodtechnology.2020.2.12 
scientists took the sample from a patient and analysed the genome sequence of the virus on $7^{\text {th }}$ January 2020. They shared the full genetic sequence of SARS-CoV-2 publicly on $12^{\text {th }}$ January 2020 (World Health Organization, 2020a). The World Health Organization (WHO) named the SARS-CoV-2 infectious disease as coronavirus disease 2019 (COVID-19) on 11th February 2020 (World Health Organization, 2020a). They announced COVID-19 as a pandemic outbreak on $12^{\text {th }}$ March 2020. It is a highly pathogenic virus. Till $6^{\text {th }}$ October 2020 , about 214 countries and territories around the world and two international conveyances had been affected by COVID-19 (World Health organization, 2020a). As of $6^{\text {th }}$ October 2020, a total of $36,041,783$ coronavirus cases; 1,054,604 death cases and 27,145,526 recovered cases have been reported throughout the world (Coronavirus outbreak, 2020). In the United States of America (USA), more than 7 million $(7,722,746)$ people were affected by COVID-19 (Coronavirus outbreak, 2020). Worldwide, the highest number of death cases $(215,822)$ has been confirmed in the USA (Coronavirus outbreak, 2020). The number of new cases is growing exponentially in the USA, India, Brazil, Russia, Colombia, Spain, Peru, Argentia and Mexico.

\section{SARS-COV-2}

\section{Morphology and Genome Characterization}

Coronaviruses are classified into four genera, which are alpha $(\alpha)$, beta $(\beta)$, gamma $(\gamma)$ and delta $(\Delta)$ coronavirus. There are six possible human coronaviruses $(\alpha-\mathrm{HCoV}$ NL63, $\alpha$-HCoV-229E, $\beta$-HCoV-OC43, $\beta$-HCoV-HKU1, $\beta$-SARS-CoV, and $\beta$ MERS-CoV. $\beta$-SARS-CoV and $\beta$-MERS-CoV) cause severe respiratory tract infections (Lim et al., 2016). The other four human coronaviruses lead to mild respiratory symptoms like a common cold due to their low pathogenicity. $\beta$-SARS$\mathrm{CoV}$ and $\beta$-MERS-CoV share some common viral structural protein features, such as spike glycoprotein (S), envelope (E), membrane (M) and nucleocapsid (N) (Lim et al., 2016).

The SARS-CoV-2 $\beta$-coronavirus belongs to the Coronaviridae family, Coronavirinae suborder, which is classified under the Nidovirales order. It is an enveloped, nonsegmented positive-sense and single-stranded RNA virus (Richman et al., 2016). It contains a large RNA genome of about $30 \mathrm{~kb}$. The viral particle (virion) is spherical, 60-140 $\mathrm{nm}$ in diameter, with spikes of about 9-12 nm. The mRNA transcript comprises a 5' terminal cap structure and a 3' poly A-tail. SARS-CoV-2 consists of a mRNA transcript wrapped in a helical symmetrical nucleocapsid which is surrounded by an envelope comprising a $150 \mathrm{kDa}$ surface/spike glycoprotein, a $25-30 \mathrm{kDa}$ membrane protein and an 8-12 kDa envelope small membrane protein pentamer. The rep gene (viral replicase gene) encodes the first two open reading frames (orfla and orflb). Orf1a and Orf1b are polyproteins involved in the co-translation proteolysis process. It consists of two-third of the genome at the 5' end. The accessory proteins (Orf3a, Orf6, Orf7a, Orf8 and Orf10) contribute to pathogenesis. Table 1 describes the genome characterization of SARS-CoV-2 (Lim et al., 2016; Fehr and Perlman, 2015). 
Table 1. The genome characterization of SARS-CoV-2.

\begin{tabular}{ll}
\hline & SARS-CoV-2 \\
\hline Length of DNA nucleotides & 29,903 \\
Open reading frame (orf) & Orf1a, Orf1b, Orf3a, Orf6, Orf7a, Orf8, Orf10 \\
Structural protein & 4 (S, E, M, N) \\
Spike protein (S) & $21562-25383$ \\
Envelope protein (E) & $26244-26471$ \\
Matrix protein (M) & $26522-27190$ \\
Nucleocapsid protein (N) & $28273-29532$ \\
Accessory proteins & 5 (Orf3a, Orf6, Orf7a, Orf8, Orf10) \\
A characteristic gene order & 5'- replicase Orf1a, Orf 1b, spike, Orf3a, envelope, \\
& membrane, Orf6, Orf7a, Orf8, nucleocapsid, Orf10-3' \\
& with short untranslated regions (UTRs) at both termini \\
\hline
\end{tabular}

The spike protein is actively involved in binding between the host cell receptor and the virion. It allows the viral particles to enter the host cells. It is the main therapeutic target for drug designing. The membrane protein maintains the shape of the virion. It also enhances the curvature of the membrane and helps in binding to the nucleocapsid. The envelope protein actively participates in the assembly and release of virions. The ion-channel activity in the SARS-CoV-2 E protein is vital for pathogenesis. The nucleocapsid protein is essential for RNA synthesis and packaging the genome into virions (Fehr and Perlman, 2015; Ou et al., 2020).

A respiratory sample from a COVID-19 patient was analysed using the next sequencing tool. The Chinese scientists found that SARS-CoV-2 is a novel member of the beta coronavirus family that infect humans using phylogenetic tree analysis. It is a deadly virus. It has a genetic similarity with SARS-CoV and MERS-CoV. The SARSCoV-2 shares $79 \%$ sequence similarity with SAR-CoV, while $50 \%$ is identical to MERS-SARS (Singhal, 2020; Moreno et al., 2017; Xu et al., 2020; Song et al., 2019). However, it is still different from coronaviruses that cause SARS-CoV and MERS$\mathrm{CoV}$ in humans.

In 2013, the scientists identified that the genome sequence of SARS-CoV-2 was about 96.3\% genetically homologous to a Yunnan Rhinolophus affinis (bat) coronavirus RaTG13. SARS-CoV-2 is more closely related to bat SARS-like-virus-CoVZC45 (MG772933.1) (more than 85\% homology identity) and bat-SL-CoVZXC21 (MG772934) which has 89\% genome similarity. Bat-SL-CoVZXC21 was obtained from the Southwest of China (Moreno et al., 2017; Xu et al., 2020; Song et al., 2019). Bats are the natural reservoirs for human pathogenic diseases like SARS, MERS and COVID-19. Researchers from the South China Agriculture University found that pangolins may be one of the intermediate sources for SARS-CoV-2. They isolated the virus from the pangolin, analysed and reported that the virus was $99 \%$ identical to the human SARS-CoV-2 strain using metagenomic RNA sequencing (Xu et al., 2020). 


\section{Pathogenesis}

The virus infection is initiated by the attachment of SARS-CoV-2 virus particles to the Human Angiotensin-converting enzyme 2 (hACE2) through the spike protein (Ceccarelli et al., 2020). hACE2 is an entry host receptor for SARS-CoV and SARS-CoV-2. It is a zinc-binding carboxypeptidase transmembrane glycoprotein. It mostly targets the lungs and host immune system.

The spike protein consists of two domains, which are S1 and S2. The binding between the S1 domain and its linked receptor enhances the $\mathrm{S}$ protein's conformational change. After that, it triggers the interaction between the viral particle and the host cell membrane via the S2 domain. Finally, the virus enters the host cell through the endosomal pathway. The cysteine protease cathepsin L1 (CTSL1) can also help in the membrane fusion between the virion and the host cell at the low $\mathrm{pH}$ in the cellular environment. This host protease promotes the endosomal virus entry into the cell membrane during the SARS-CoV-2 infection via proteolytic cleavages which activate the $S$ protein. The transmembrane protease serine 2 (TMPRSS2) and trypsin-like protease (TMPRSS11D) are human airway proteases. They are located on the host cell surface membrane which carries out the cleavage of the S1/S2 domain, to trigger the S protein for the entry of the virus into the host cells via the non-endosomal pathway (Lim et al., 2016; Fehr and Rehman, 2015; Ou et al., 2020).

Then, the viral RNA is released into the cytoplasm. Orf $1 \mathrm{a}$ and Orf $1 \mathrm{~b}$ are translated via the ribosomal frameshifting mechanism to generate polypeptide 1a (pp1a) and polypeptide $1 \mathrm{~b}(\mathrm{pp} 1 \mathrm{~b})$. The polypeptides are cleaved by the host and the viral proteases to produce non-structural proteins (NSPs). Afterwards, they are assembled to form the RNA replicase-transcriptase complex. This complex mainly participates in the replication of the virus. The sub-genomic RNAs are transcribed and translated to build the structural and accessory proteins. The viral progeny particles are packaged and assembled from genomic RNA containing nucleocapsid and other structural proteins, such as the S, E and M proteins in the cytoplasm. Then, they bud into the lumen of the endoplasmic reticulum-Golgi intermediate compartment (ERGIC) and come out as a smooth-wall vesicle on the plasma membrane through exocytosis. Lastly, the matured virions are released from the infected cell and spread to new host cells (Lim et al., 2016; Fehr and Rehman, 2015; Ou et al., 2020). The viral infectious cycle will begin again

\section{Transmission and clinical manifestations}

SARS-CoV-2 is a highly pathogenic virus. It spreads easily from human to human. It is transmitted via respiratory secretions such as fluid droplets when an infected person coughs or sneezes (Singhal, 2020; Adhikari et al., 2020; Yang and Wang, 2020). In the early stage, it causes fever, dry cough and tiredness; Later on there are subsequent onsets of respiratory clinical manifestations such as shortness of breath and lung infection. In severe cases, it causes life-threatening pneumonia, bronchiolitis and organ failure (eg. kidney, heart and liver) (Huang et al., 2020). Centres for Disease Control and Prevention have found new signs of COVID-19, such as aches and pains, nasal congestion, headache, conjunctivitis, sore throat, 
diarrhoea, loss of taste or scent, skin rash or finger or toe discoloration (World Health Organization, 2020b). Some patients may get these less common symptoms. The SARS-CoV-2 infection might leads to the disruption of the immune system by decreasing the innate immune responses with delayed activation of proinflammatory signals from the chemokines and cytokines.

Elderly people, pregnant ladies, children, immune-compromised patients (e.g. human immunodeficiency virus (HIV) and cancer patients) and people with chronic diseases like hypertension, diabetes, lung, kidney and heart problems are highly susceptible to the SARS-CoV-2 infection.

\section{Preventive measures}

As the growth of positive COVID-19 cases in the world has been increasing gradually, preventive measures against COVID-19 are essential. Some of the most important preventive measures are: avoid handshaking; wear a mask and gloves; wash hands regularly with soap and water; use hand sanitizer frequently especially before and after touching the lock key, keyboard, mouse, keys, credit cards, lift buttons, laptop and hand phone; avoid using a cloth mask because it is not as effective as the surgical mask or N95 respirators; avoid going to crowded place such as restaurants, markets, parks, shopping malls, cinema theatres, etc.; thoroughly cook meat and eggs; avoid attending mass events or gatherings like weddings, conferences, etc.; cover the mouth and nose when coughing or sneezing; avoid contact with anyone who coughs or sneezes; maintain social distancing (about 1 metre); stay at home when not feeling well; stop hunting, selling and eating wild animals such as bats, snakes, pangolins, etc.; avoid travelling to COVID-19 affected areas and countries; undergo health screening for COVID-19 after returning home from overseas; self-quarantine by staying at home for 14 days after getting back home from abroad, or developing fever, dry cough, shortness of breath, chills, frequent shaking with chills, muscle pain, headache, sore throat and loss of taste or odour; avoid spreading false information about COVID-19 through social media such as Facebook, Instagram, Twitter, etc; throw the used masks and gloves into the dustbin. Some countries are still enforcing the 'Movement Control Order' such as Singapore, Malaysia, India, etc. to control the spread of the virus infection. Some countries have announced that it will be mandatory for people to wear face masks in public places such as markets, restaurants, shopping malls, religious places (temples, churches and mosques), and public transportation like on the bus, train and taxi. People failing to observe this act are fined. The immigration department of some countries banned nationals from countries which had a high numbers of COVID19 cases such as the USA, India, Brazil, Russia, Colombia, Peru, Spain, Argentina, Mexico, South Africa, etc., from entering their countries. Worldwide, digital technologies are used to raise the awareness of the public health response to fight against COVID-19, such as monitoring and tracing contact, positive case identification, etc. Currently, at least 29 countries are using digital technology (mobile data) to trace contacts. For example, South Korea implemented a contact tracing application successfully. This application allows nationals to record their locations. Besides, it draws on data from credit card and telecommunication companies. In Singapore, they launched the 'TraceTogether' application on $20^{\text {th }}$ March 2020 to curb the spread of 
COVID-19 cases. In Malaysia, three major mobile applications such as Gerak Malaysia, MySejahtera and MyTrace have already been launched to the purpose of contact tracing.

\section{The ability of Indian spices to enhance the immune system against COVID-19}

Scientists from different countries are still working on finding the vaccine or effective medicine for COVID-19. However, no vaccine or no specific anti-viral treatment against COVID-19 has been available so far. Thus, the SARS-CoV-2 infection can be prevented by blocking inflammation and enhancing the body's immune system. The inhibition of inflammatory mediators on the transcriptional level can block the inflammation. NF- $\mathrm{kB}$ is a major transcription factor which regulates several vital physiological processes such as inflammation, oxidative stress, immune responses, certain viral gene expression, cell growth and apoptosis (Gilmore and Herscovitch, 2006). It is actively involved in the development of adaptive and innate immunity (Golan-Goldhirsh and Gopas, 2014). Therefore, NF$\kappa \mathrm{B}$ could be a potential target for inflammation-based viral therapy.

Plant compounds are able to target the multiple steps in the NF-kB pathway. They hinder the phosphorylation or the ubiquitination of signalling molecules. Therefore, they inhibit the degradation of the NF- $\mathrm{BB}$ inhibitor (IкB). They interfere with the $\mathrm{NF}-\mathrm{\kappa B}$ translocation from the cytoplasm to the nucleus, and modify the expression of the pro-inflammatory transcription genes such as cytokines, lipoxygenase, nitric oxide synthases (NOS) and cyclooxygenase (COX). They also block the interaction between the NF- $\mathrm{KB}$ and the target DNA. The plant compound binds to the target DNA and shuts off the transcriptional activity of NF-KB (Seo et al., 2018).

Since 5000 B.C., spices have been extensively used for medical treatment, or as colouring agents, flavouring agents and preservatives in cooking (Kunnumakkara et al., 2018). Indian food cannot possibly be imagined without spices. Moreover, numerous studies have reported that phytochemicals derived from spices (e.g. cardamom, fennel seed, chilli, clove, cassia bark, black pepper, long pepper, cumin, coriander, nutmeg, bay leaf, star anise, onion, mustard, asafoetida, mint, fenugreek, turmeric, garlic, ginger, etc.) prevent and cure different types of chronic diseases via targeting inflammatory pathways. Indian spices have been identified as a class of promising anti-inflammatory, anti-oxidative, anti-viral and immunomodulatory agents. Table 2 shows the Indian spices and their mode of action (Yahfoufi et al., 2018; Tzeng et al., 2015; Chojnacki et al., 2015; Thummuri et al., 2015; Gruenwald et al., 2010; Zhai et al., 2016; Iacobellis et al., 2005; Lee et al., 2009; Cianciulli et al., 2016; Tang et al., 2015; Bachiega et al., 2012; Schmitz et al., 2015). 


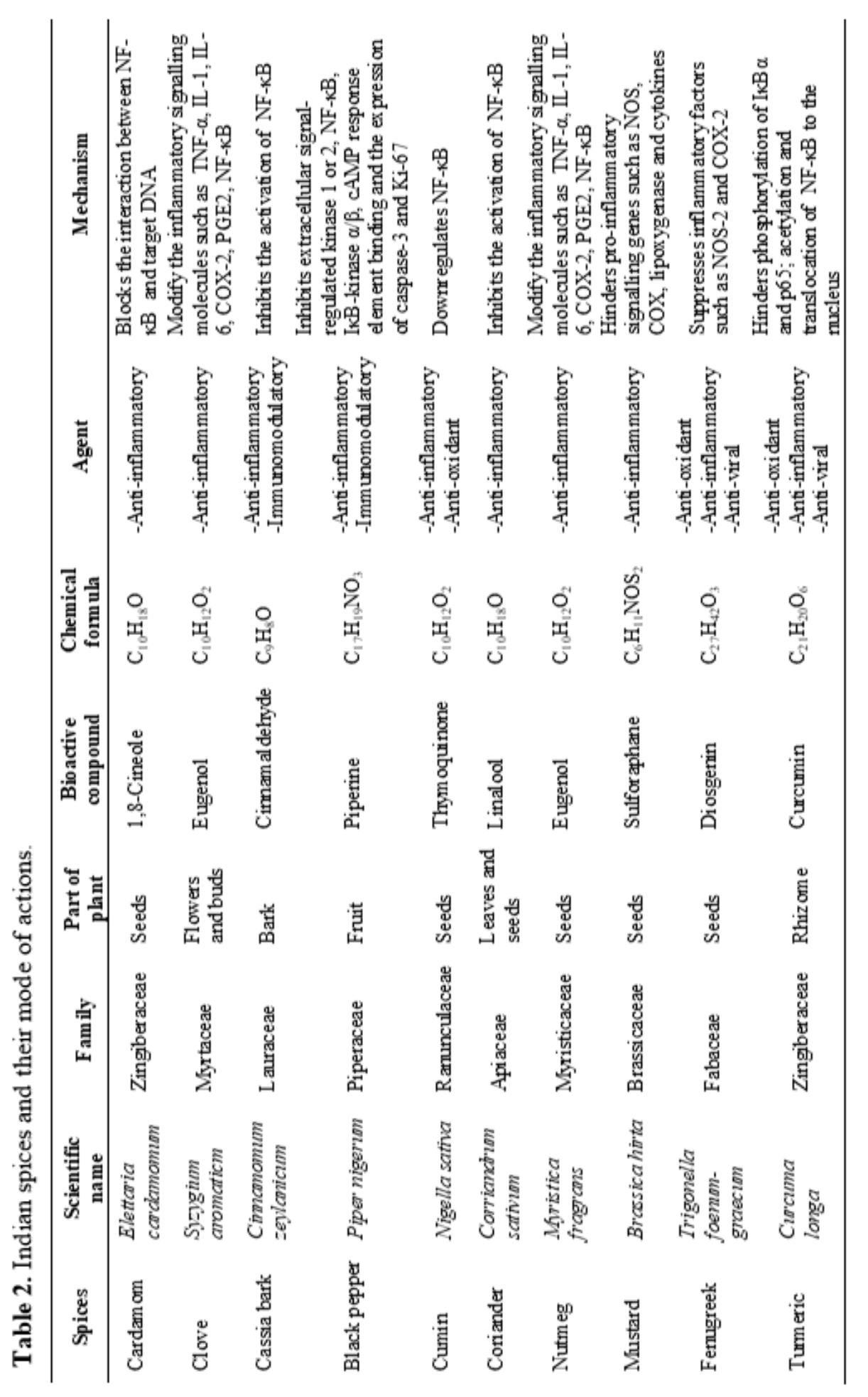




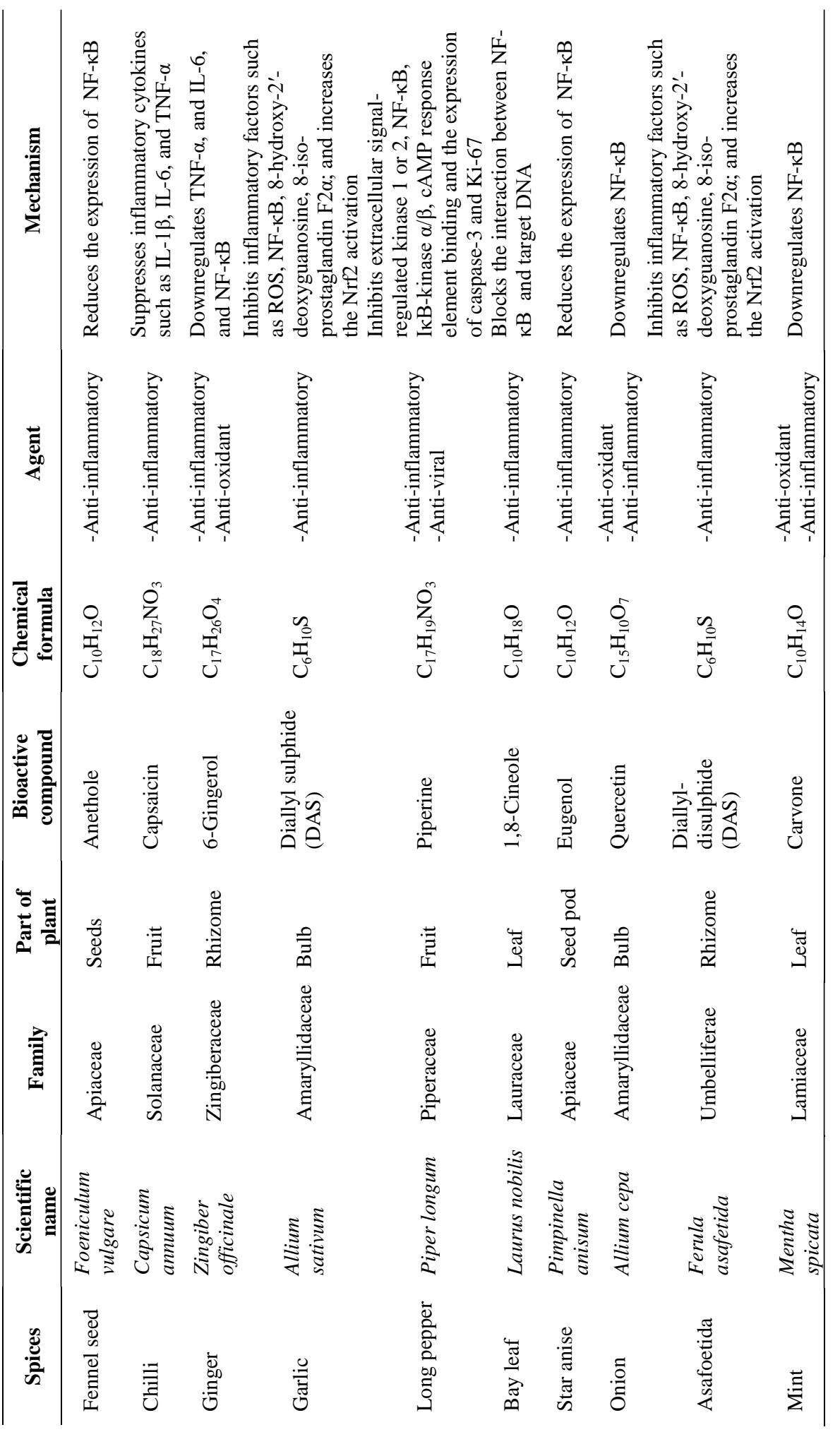




\section{Major components of Indian spices and their role in the inflammation pathway}

\section{1,8-Cineole}

1,8-Cineole (Eucalyptol) is a natural organic compound derived from different types of plants, such as cardamom and bay leaf. It is a cyclic ether and monoterpene oxide. It has a significant pharmacological activity against respiratory ailments, such as anti-inflammatory and bronchodilatory conditions. It is used to treat a variety of respiratory and inflammatory disorders (Galan et al., 2020). Moreover, it has been proven that it downregulates the NF- $\mathrm{kB}$ expression in humans. Based on the study by Li et al. (2016), it was shown that 1,8-Cineole protects against infection with the influenza virus in mice by modulating pulmonary inflammatory signalling responses. 1,8-Cineol significantly reduced the expression of interleukin(IL)-4, IL-5, IL-10, and monocyte chemotactic protein-1 (MCP-1) in nasal irrigation fluids, and the expression of IL-1 $\beta$, IL-6, tumour necrosis factor-alpha (TNF- $\alpha$ ), and interferon gamma (IFN- $\gamma$ ) in the lung tissues of mice infected with influenza virus. Moreover, the study proved that 1,8-Cineol efficiently lowered the level of NF- $\mathrm{kB}$ p65, ICAM-1, and VCAM-1 in lung tissues. According to Müller et al. (2016), 1,8-Cineol increased the anti-viral transcription factor IRF3 expression in a human ex vivo model of rhinosinusitis. At the same time, it lowered the activity of the pro-inflammatory NF- $\mathrm{kB}$ in that model. Brown et al. (2017) reported that chronic obstructive pulmonary disease (COPD) patients who took $200 \mathrm{mg}$ 1,8-cineole orally, three times per day for six months, showed a significant reduction in their symptoms like coughing, dyspnea and breathing issues.

\section{Eugenol}

Eugenol (allyl chain-substituted guaiacol) is the phenolic component derived from essential oil. Clove, cinnamon, nutmeg, basil, bay leaf and black pepper are wellknown sources of eugenol. It inhibits the activity of the COX-2 and TNF- $\alpha$ in cells. It also suppresses the activation of NF- $\mathrm{KB}$. Furthermore, it blocks the proinflammatory cytokine expression in macrophages. The inhibitory effect on the synthesis of prostaglandin and the chemotaxis of neutrophils/ macrophages actively participate in its anti-inflammatory mechanism mode. Tragoolpua and Jatisatienr (2007) found that eugenol could destroy the virions' envelopes and block viral replication at the early stage of the infectious cycle. The active phytocomponent, eugenol from the clove extracts (flower buds and essential oil) showed anti-viral activity against HSV-1 and HSV-2. Based on Lane et al. (2019), it was concluded that a low concentration of eugenol (EC50 of $1.3 \mu \mathrm{M})$ could kill the Ebola virus. Another study on the administration of eugenol at 5 and $10 \mathrm{mg} \mathrm{kg}^{-1}$ in lipopolysaccharide induced acute lung injury mice showed significant results for anti-inflammation activity (Huang et al., 2015). This was because eugenol suppressed the expression of the pro-inflammatory cytokines. Pramod et al. (2010) found that clove oil $(200 \mathrm{mg} / \mathrm{kg})$ could prevent macrophages from producing cytokines in lung injured-mice. Furthermore, it was shown it acts as an anti-viral agent for feline calicivirus, tomato yellow leaf curl virus, human influenza A (HIA) virus and four airborne diseases. 


\section{Cinnamaldehyde}

Cinnamaldehyde is a natural phenylpropanoid component of essential cinnamon oil. It has a variety of pharmacological uses, such as anti-inflammatory, anti-viral, anti-oxidant, anti-immunomodulatory, anti-bacterial, anti-cancer and anticholesterol. Li et al. (2017) carried out an experiment on the administration of cinnamaldehyde in mice infected with coxsackievirus B3 (CVB3). The results showed that the active component of cinnamon decreased the viral titre. It inhibited the viral replication in mice. It also downregulated the expression of nitric oxide (NO), NF- $\mathrm{KB}$ and pro-inflammatory cytokines in the CVB3 infected mice. Based on Zhang et al. (2018), cinnamaldehyde increased the level of IL-6, TNF- $\alpha$, IFN- $\gamma$, and NO, while decreasing the expression of the IL-2, SOD and GSH in the lung of viral pneumonia infected mice. It reduced viral production and inflammation in lung damaged tissues. Another study concluded that cinnamaldehyde exerted antiviral activity against HSV-2 (Toujani et al., 2018). The study proved that the lowest $\mathrm{EC}_{50}$ value $(2.3 \mu \mathrm{g} / \mathrm{ml})$ suppressed the viral particles' infectiousness in the human cell.

\section{Piperine}

Piperine is an amide alkaloid derived from the fruits of the black, white and long pepper extracts. It has been reported to have different types of biological and pharmaceutical therapeutic effects, such as anti-inflammatory, anti-viral, analgesic, anti-convulsant and anti-cancer. It is also used to treat gastrointestinal diseases, inflammatory disorders like asthma, Alzheimer's disease (AD), Parkinson's disease, arthritis, gastritis and endometritis. The anti-inflammatory properties of piperine suppress the inflammatory signalling expression in chronic disorders through NF- $\kappa$ B, MAPK, AP-1, COX-2, NOS-2, IL-1 $\beta$, TNF- $\alpha$, PGE2 STAT3. According to Rathee et al. (2018), the Aegle marmelos plant extract in combination with piperine shows promising results of hepatoprotective activity via the antioxidant and anti-inflammatory effects. Mair et al. (2016) showed that the piperine phytocomponent from the Piper nigrum fruit extract inhibited the CVB3 activity at $\mathrm{IC}_{50}$ of $10.6 \mu \mathrm{g} / \mathrm{ml}$.

\section{Thymoquinone}

Thymoquinone is a monoterpene compound found in the seeds of black cumin. It possesses a variety of pharmaceutical activities, such as anti-oxidant, antiinflammatory, anti-cancer, immunomodulatory, anti-viral and anti-bacterial. Umar et al. (2016) demonstrated that thymoquinone combined with curcumin exerts antiviral activity against the avian $\mathrm{H} 9 \mathrm{~N} 2$ virus in turkeys. The combination therapy decreased the pro-inflammatory cytokine expression; and it simultaneously inhibited the pathogenic mechanism of the H9N2 virus. Another study (2013) reported that a hepatitis $\mathrm{C}$ virus (HCV) patient was given $450 \mathrm{mg}$ of black cumin oil three times per day, for three months continuously (Barakat et al., 2013). The results showed that the black cumin reduced the viral titre and improved the oxidative stress in the patient. 


\section{Linalool}

Linalool is a monoterpene isolated from the coriander leaf extract. It is also present in cinnamon, rosemary, basil, cardamom and thyme. Lee et al. (2018) administered linalool $(5.2 \mathrm{mg} / \mathrm{kg})$ in endotoxin-injected mice. The results showed that it promisingly decreased the expression levels of IL-1 $1 \beta$, IL-18, TNF- $\alpha$ and IFN- $\gamma$ in the infected mice. Forouzanfar et al. (2014) carried out an experiment on the antiinflammatory effect of linalool in Wistar rat-induced paw edema. It repressed the secretion of the cytokine by activated T-cells. It also lowered the IL-2, TNF- $\alpha$ and IFN- $\gamma$ expression in the infected rat.

\section{Sulforaphane}

Sulforaphane is the active anti-inflammatory compound of mustard leaf extract. It is an isothiocyanate (group of sulphur containing organic compounds). According to Furuya et al. (2016), it was reported that sulforaphane suppressed the human immunodeficiency virus (HIV) infection via the transcription of the regulator Nrf2 in macrophages. Sulforaphane blocked the infection before the formation of long terminal repeat (2-LTR) viral DNA circles in HIV infected cells. Yu et al. (2016) demonstrated that sulforaphane inhibited the expression of HCV protein and RNA in replicon cells with the minimum inhibitory concentration $\left(\mathrm{IC}_{50}\right)$ of $5.7 \mu \mathrm{m}$ by degrading the phosphorylation of $\mathrm{PI} 3 \mathrm{~K}$ via Nrf2/HO-1 signalling pathway.

\section{Diosgenin}

Diosgenin is a steroidal sapogenin phytocompound isolated from fenugreek seed extract. It has been reported to play a vital pharmalogical role in a variety of diseases as an anti-viral, anti-oxidant, anti-inflammatory, anti-diabetic, or in hypercholesterolemia and gastrointestinal disorders. Wang et al. (2011) evaluated the effect of diosgenin against the anti-viral activity of HCV. They found that disogenin suppressed the replication of HCV at the lowest concentration (EC50) of $3.8 \mu \mathrm{M}$. Diosgenin decreased the expression of the viral mRNA and subsequently the viral replication via lowering the expression of STAT3. Kim et al. (2016) concluded that diosgenin significantly reduced phthalic anhydride (PA)-induced skin inflammation in mice by repressing the level of IL-4 and IL-6.

\section{Curcumin}

Curcumin is a natural polyphenol bioactive compound present in the turmeric plant. It has been shown to possess pharmalogical therapeutic effects, like antiinflammatory, anti-oxidant, anti-viral, anti-bacterial and anti-fungal. Avasarala et al. (2013) performed an experiment on the anti-inflammatory effects of curcumin in reovirus induced-acute respiratory distress syndrome (ARDS) infected mice. The infected mice were treated with curcumin $(50 \mathrm{mg} / \mathrm{kg}$ ) for five days. Curcumin significantly reduced the expression of pro-inflammatory cytokines such as IL-6, IL-10, IFNc, and MCP-1 via decreasing the phosphorylation of NF- $\mathrm{kB}$ p65. Moreover, curcumin blocked the reovirus pathogenesis in infected mice by lowering the expression of the TGFß Receptor II, which is important in the TGFß signalling pathway. According to $\mathrm{Xu}$ and Liu (2017), it was demonstrated that curcumin decreased the expression of pro-inflammatory cytokines in influenza A 
(IA) virus infected-human macrophages and mice immune cells through the NF- $\mathrm{KB}$ signalling pathway. Curcumin triggered the expression of NF- $\kappa \mathrm{B} 1$ and $\mathrm{I} \kappa \mathrm{B} \alpha$ inhibitors. Finally, it impeded the translocation of p65 from the cytoplasm to the nucleus in order to prevent the viral replication of the IA.

\section{Anethole}

Anethole is a natural aromatic compound (phenlypropanoid) derived from essential oils. It is present in star anise and fennel seed. Wang et al. (2018) evaluated the anti-inflammatory effects of anethole in chronic constriction injury (CCI)-induced neuropathic pain in mice. They found that anethole suppressed the TNF- $\alpha$, IL-6 and IL-1 $\beta$ expression in infected mice. At the same time, the expression of antiinflammatory cytokine (IL-10) increased. Another study stated that anethole manifested anti-viral activity against HSV-1 via inhibited the viral production. It decreased the viral infectiousness by $>99 \%$ (Marinov and Valcheva-Kuzmanova, 2015).

\section{Capsaicin}

Capsaicin is a phytocompound isolated from the chili peppers. Based on Zhang et al. (2019), capsaicin (1 mg/kg) was administered in concanavalin A (Con A)induced hepatitis mice. The results showed a significantly reduced level of the IL$1 \beta$, IL- 6 , and TNF- $\alpha$, while enhancing the expression of the liver X receptor $\alpha$ $(\operatorname{LXR} \alpha)$ in the infected mice. Zheng et al. (2018) investigated the antiinflammatory effects of capsaicin in lipopolysaccharide-stimulated BV2 microglial cells. They reported that capsaicin decreased the expression of the NO, TNF- $\alpha$ and IL-1 $\beta$ in cells. Furthermore, it promoted the I $\kappa \mathrm{B} \alpha$ expression while blocking the translocation of NF- $\mathrm{kB}$ p 65 from the cytoplasm to the nucleus. It also inhibited the NOS and COX-2 activities in cells. It hindered the activation of NF- $\kappa B$. Thus, it blocked the pro-inflammatory signalling responses in the infected cells.

\section{6-Gingerol}

6-Gingerol is a major bioactive component of the turmeric plant. It has been described as possessing anti-inflammatory, anti-viral, anti-bacterial, anti-diabetic, anti-oxidant and anti-cancer effects. El-Deeb et al. (2018) investigated 6-gingerol effects in HCV infected peripheral blood mononuclear cells. The result showed that 6-gingerol modulated the expression of TNF- $\alpha$, IL-2 \& IL-8 in the infected cells. It decreased the production of the pro-inflammatory cytokines in the cells. Another study demonstrated that 6-gingerol $(100 \mu \mathrm{mol} / \mathrm{L})$ may be administered to nonalcoholic steatohepatitis (NASH) infected mice (Tzeng et al., 2015). 6-gingerol lowered the expression of the MCP-1, TNF- $\alpha$, IL- 6 and NF- $\kappa$ B in infected mice.

\section{Diallyl sulphide (DAS)}

Diallyl trisulfide is an organosulphur compound isolated from garlic. It possesses a variety of pharmaceutical properties, like anti-viral, anti-inflammation, antibacterial, anti-cholesterol and anti-oxidant. It has been used to treat asthma, cancer, heart disease, osteoarthritis and acute or chronic liver injury. Hall et al. (2017) carried out an experiment on the anti-viral activity of DAS against the dengue virus (DENV). They treated the human cells infected with DENV-2 NGC (New Guinea 
C) virus with four different concentrations $(10,50,250,1000 \mu \mathrm{M})$ of DAS compounds. The results showed that DAS suppressed the pro-inflammatory immune responses (TNF- $\alpha$, IL- 8 \& IL-10). It blocked the viral pathogenesis by inhibiting the production of NO, oxidative injury and the expression of ROS. According to $\mathrm{Li}$ et al. (2019), $\mathrm{CCL}_{4}$ induced mice were fed with three varying concentrations of DAS $\left(100,200\right.$, or $\left.400 \mu \mathrm{mol} \mathrm{kg}^{-1}\right)$ to study the anti-inflammatory effects of DAS on liver injured mice. They concluded that DAS triggered the phosphorylation of $\mathrm{I} \kappa \mathrm{B} \alpha$ and reduced the expression of $\mathrm{NF}-\kappa \mathrm{B}$ p65 in the cytoplasm. Therefore, it blocked the translocation of NF- $\mathrm{kB}$ p65 from the cytoplasm to the nucleus. Furthermore, it lowered the TNF- $\alpha$ expression in liver injured mice.

\section{Quercetin}

Quercetin is a polyphenol (flavonoid) derived from onion. It has pharmalogical properties such as anti-viral, anti-inflammatory, anti-microbial, anti-allergic, antiasthmatic and anti-oxidant. Based on Ganesan et al. (2012), it was reported that quercetin suppressed the phosphorylation of Akt, and the pro-inflammatory cytokines (IL-8) and interferon (IFN) signalling responses in mice infected with the rhinovirus (RV). It also blocked viral endocytosis, viral replication, the formation of RV capsid protein, RV-induced eIF4GI cleavage abrogation, and upregulated eIF $2 \alpha$ phosphorylation. It inhibited the infectious and pathogenetic mechanism of $\mathrm{RV}$ and enhanced the lung function in the infected mice. According to $\mathrm{Yu}$ et al. (2007), it was shown that quercetin inhibited HIV-1 reverse transcriptase activity at the low concentration $\left(\mathrm{IC}_{50}\right)$ of $60 \mu \mathrm{M}$. Therefore, it blocked the HIV-1 virus replication.

\section{Carvone}

Carvone is a bioactive compound isolated from Peppermint oil (essential oil). Its applications as anti-viral, anti-bacterial, anti-inflammatory, anti-cancer and antioxidant are well known, due to its pharmalogical and biological properties. Based on Jusoh et al. (2018), carvone could be a potential neuraminidase (NA) inhibitor. Carvone bound successfully with the neuraminidase active site of the influenza virus at the lowest binding energy of $8.30 \mathrm{kcal} / \mathrm{mol}$ measured using a computational biology tool. It blocks the NA function via preventing the viral endocytosis action.

\section{Conclusions}

During the COVID-19 pandemic outbreak, the consumption of good food is very important to maintain a healthy life. Fresh vegetables (e.g. carrots, spinach, broccoli, cauliflower, beetroot, etc.) and fruits (guava, apple, lemon, orange, etc.) always protect us against diseases. A strong immune system acts as a barrier against any pathogen entering our body. There is no specific food that can cure COVID-19. However, adding spices to food can boost up the immune system. 'Rasam' is a South Indian soup that is made with tomatoes, tamarind, along with spices such as cumin, fennel seed, garlic, black pepper, chilli, turmeric, coriander, 
mustard and curry leaves. This soup mainly consists of spices. It is also called herbal soup. It helps to fight off the COVID-19 symptoms and enhance the body's immune system. Rasam is normally served with plain rice. It can be the main dish or just a drink after the meal. All the South Indian restaurants serve rasam with plain rice. It helps in digestion, combating flu, cough and regulates an upset stomach. In conclusion, spices regulate immunity by interfering with the inflammatory factors such as COX, NOS, cytokines, lipoxygenase, growth factors (TNF- $\alpha$, interleukins) in the NF- $\kappa$ B pathway. They may be viewed as promising anti-viral agents for the prevention of the COVID-19 disease.

\section{Acknowledgements}

I would like to thank the frontliners who are helping to face the COVID-19 pandemic outbreak.

\section{References}

Adhikari, S.P., Meng, S., Wu, Y.J., Mao, Y.P., Ye, R.X., Wang, Q.Z., Sun, C., Rozelle, S., Raat, H., Zhou, H. 2020. Epidemiology, causes, clinical manifestation and diagnosis, prevention and control of coronavirus disease (COVID-19) during the early outbreak period: a scoping review. Infectious Diseases of Poverty, 9(1), 1-12.

Avasarala, S., Zhang, F., Liu, G., Wang, R., London, S.D., London, L. 2013. Curcumin modulates the inflammatory response and inhibits subsequent fibrosis in a mouse model of viral-induced acute respiratory distress syndrome. PloS One, 8(2), e57285.

Bachiega, T.F., de Sousa, J.P.B., Bastos, J.K., Sforcin, J.M. 2012. Clove and eugenol in noncytotoxic concentrations exert immunomodulatory/anti-inflammatory action on cytokine production by murine macrophages. Journal of Pharmacy and Pharmacology, 64(4), 610-616.

Barakat, E.M.F., El Wakeel, L.M., Hagag, R.S. 2013. Effects of Nigella sativa on outcome of hepatitis C in Egypt. World Journal of Gastroenterology: WJG, 19(16), 2529.

Brown, S.K., Garver, W.S., Orlando, R.A. 2017. 1, 8-cineole: An Underappreciated Antiinflammatory Therapeutic. Journal of Biomolecular Research and Therapeutics, 6(1), 154.

Ceccarelli, M., Berretta, M., Rullo, E.V., Nunnari, G., Cacopardo, B. 2020. EditorialDifferences and similarities between Severe Acute Respiratory Syndrome (SARS)CoronaVirus $(\mathrm{CoV})$ and SARS-CoV-2. Would a rose by another name smell as sweet?. European Review for Medical and Pharmacological Sciences, 24, 2781-2783.

Chojnacki, J.E., Liu, K., Saathoff, J.M., Zhang, S. 2015. Bivalent ligands incorporating curcumin and diosgenin as multifunctional compounds against Alzheimer's disease. Bioorganic \& Medicinal Chemistry, 23(22), 7324-7331.

Cianciulli, A., Calvello, R., Porro, C., Trotta, T., Salvatore, R., Panaro, M.A. 2016. PI3k/Akt signalling pathway plays a crucial role in the anti-inflammatory effects of curcumin in LPSactivated microglia. International Immunopharmacology, 36, 282-290.

Coronavirus Outbreak. 2020. [Online URL: https://www.worldometers. info/coronavirus/] accessed on May 15, 2020. 
El-Deeb, N., El-Adawi, H., Sharaf, M., El Enshasy, H.A. 2018. Targeting pro-inflammatory cytokines and chemokine as potential novel strategy in adjuvant development for antiHCV therapy. Journal of Scientific \& Industrial Research, 77, 510-515.

Fehr, A.R., Perlman, S. 2015. Coronaviruses: an overview of their replication and pathogenesis. In Coronaviruses (pp. 1-23). Humana Press, New York, NY.

Forouzanfar, F., Bazzaz, B.S.F., Hosseinzadeh, H. 2014. Black cumin (Nigella sativa) and its constituent (thymoquinone): a review on antimicrobial effects. Iranian Journal of Basic Medical Sciences, 17(12), 929.

Furuya, A.K.M., Sharifi, H.J., Jellinger, R.M., Cristofano, P., Shi, B., de Noronha, C.M. 2016. Sulforaphane inhibits HIV infection of macrophages through Nrf2. PLoS Pathogens, 12(4), e1005581.

Galan, D.M., Ezeudu, N.E., Garcia, J., Geronimo, C.A., Berry, N.M., Malcolm, B.J. 2020. Eucalyptol (1, 8-cineole): an underutilized ally in respiratory disorders?. Journal of Essential Oil Research, 32(2), 103-110.

Ganesan, S., Faris, A.N., Comstock, A.T., Wang, Q., Nanua, S., Hershenson, M.B., Sajjan, U.S. 2012. Quercetin inhibits rhinovirus replication in vitro and in vivo. Antiviral Research, 94(3), 258-271.

Gilmore, T.D., Herscovitch, M. 2006. Inhibitors of NF-кB signaling: 785 and counting. Oncogene, 25(51), 6887-6899.

Golan-Goldhirsh, A., Gopas, J. 2014. Plant derived inhibitors of NF-кB. Phytochemistry Reviews, 13(1), 107-121.

Gruenwald, J., Freder, J., Armbruester, N. 2010. Cinnamon and health. Critical Reviews in Food Science and Nutrition, 50(9), 822-834.

Guo, Y.R., Cao, Q.D., Hong, Z.S., Tan, Y.Y., Chen, S.D., Jin, H.J., Tan, K.S., Wang, D.Y., Yan, Y. 2020. The origin, transmission and clinical therapies on coronavirus disease 2019 (COVID-19) outbreak-an update on the status. Military Medical Research, 7(1), $1-10$.

Hall, A., Troupin, A., Londono-Renteria, B., Colpitts, T.M. 2017. Garlic organosulfur compounds reduce inflammation and oxidative stress during dengue virus infection. Viruses, 9(7), 159.

Huang, C., Wang, Y., Li, X., Ren, L., Zhao, J., Hu, Y., Zhang, L., Cheng, Z. 2020. Clinical features of patients infected with 2019 novel coronavirus in Wuhan, China. The Lancet, 395(10223), 497-506.

Huang, X., Liu, Y., Lu, Y., Ma, C. 2015. Anti-inflammatory effects of eugenol on lipopolysaccharide-induced inflammatory reaction in acute lung injury via regulating inflammation and redox status. International Immunopharmacology, 26(1), 265-271.

Iacobellis, N.S., Lo Cantore, P., Capasso, F., Senatore, F. 2005. Antibacterial activity of Cuminum cyminum L. and Carum carvi L. essential oils. Journal of Agricultural and Food Chemistry, 53(1), 57-61.

Jusoh, N., Zainal, H., Hamid, A.A.A., Bunnori, N.M., Abd Halim, K.B., Abd Hamid, S. 2018. In silico study of carvone derivatives as potential neuraminidase inhibitors. Journal of Molecular Modeling, 24(4), 93.

Kim, J.E., Go, J., Koh, E.K., Song, S.H., Sung, J.E., Lee, H.A., Kim, D.S., Son, H.J., Lee, H.S., Lee, C.Y., Hong, J.T. 2016. Diosgenin effectively suppresses skin inflammation 
induced by phthalic anhydride in IL-4/Luc/CNS-1 transgenic mice. Bioscience, Biotechnology, and Biochemistry, 80(5), 891-901.

Kunnumakkara, A.B., Sailo, B.L., Banik, K., Harsha, C., Prasad, S., Gupta, S.C., Bharti, A.C., Aggarwal, B.B. 2018. Chronic diseases, inflammation, and spices: how are they linked?. Journal of Translational Medicine, 16(1), 14.

Lane, T., Anantpadma, M., Freundlich, J.S., Davey, R.A., Madrid, P.B., Ekins, S. 2019. The natural product eugenol is an inhibitor of the ebola virus in vitro. Pharmaceutical Research, 36(7), 104.

Lee, H.S., Lee, C.H., Tsai, H.C., Salter, D.M. 2009. Inhibition of cyclooxygenase 2 expression by diallyl sulfide on joint inflammation induced by urate crystal and IL-1 $\beta$. Osteoarthritis and Cartilage, 17(1), 91-99.

Lee, S.C., Wang, S.Y., Li, C.C., Liu, C.T. 2018. Anti-inflammatory effect of cinnamaldehyde and linalool from the leaf essential oil of Cinnamomum osmophloeum Kanehira in endotoxin-induced mice. Journal of Food and Drug Analysis, 26(1), 211-220.

Li, Y., Lai, Y., Wang, Y., Liu, N., Zhang, F., Xu, P. 2016. 1, 8-cineol protect against influenza-virus-induced pneumonia in mice. Inflammation, 39(4), 1582-1593.

Li, X.Q., Liu, X.X., Wang, X.Y., Xie, Y.H., Yang, Q., Liu, X.X., Ding, Y.Y., Wang, S.W. 2017. Cinnamaldehyde derivatives inhibit coxsackievirus B3-induced viral myocarditis. Biomolecules \& Therapeutics, 25(3), 279.

Li, M., Wang, S., Li, X., Kou, R., Wang, Q., Wang, X., Zhao, N., Zeng, T., Xie, K. 2019. Diallyl sulfide treatment protects against acetaminophen-/carbon tetrachloride-induced acute liver injury by inhibiting oxidative stress, inflammation and apoptosis in mice. Toxicology Research, 8(1), 67-76.

Lim, Y.X., Ng, Y.L., Tam, J.P., Liu, D.X. 2016. Human coronaviruses: a review of virushost interactions. Diseases, 4(3), 26.

Mair, C.E., Liu, R., Atanasov, A.G., Schmidtke, M., Dirsch, V.M., Rollinger, J.M. 2016. Antiviral and anti-proliferative in vitro activities of piperamides from black pepper. Planta Medica, 82(S 01), P807.

Marinov, V., Valcheva-Kuzmanova, S. 2015. Review on the pharmacological activities of anethole. Scripta Scientifica Pharmaceutica, 2(2), 14-19.

Moreno, A., Lelli, D., De Sabato, L., Zaccaria, G., Boni, A., Sozzi, E., Prosperi, A., Lavazza, A., Cella, E., Castrucci, M.R., Ciccozzi, M. 2017. Detection and full genome characterization of two beta $\mathrm{CoV}$ viruses related to Middle East respiratory syndrome from bats in Italy. Virology Journal, 14(1), 239.

Müller, J., Greiner, J.F., Zeuner, M., Brotzmann, V., Schäfermann, J., Wieters, F., Widera, D., Sudhoff, H., Kaltschmidt, B., Kaltschmidt, C. 2016. 1, 8-Cineole potentiates IRF3mediated antiviral response in human stem cells and in an ex vivo model of rhinosinusitis. Clinical Science, 130(15), 1339-1352.

Ou, X., Liu, Y., Lei, X., Li, P., Mi, D., Ren, L., Guo, L., Guo, R., Chen, T., Hu, J., Mu, Z., Chen, X., Chen, J., Hu, K., Jin, Q., Wang, J., Xiang, Z. 2020. Characterization of spike glycoprotein of SARS-CoV-2 on virus entry and its immune cross-reactivity with SARS-CoV. Nature Communications, 11(1), 1-12.

Pramod, K., Ansari, S.H., Ali, J. 2010. Eugenol: a natural compound with versatile pharmacological actions. Natural Product Communications, 5(12), 1999-2006. 
Rathee, D., Kamboj, A., Sidhu, S. 2018. Augmentation of hepatoprotective potential of Aegle marmelos in combination with piperine in carbon tetrachloride model in wistar rats. Chemistry Central Journal, 12(1), 94.

Richman, D.D., Whitley, R.J., Hayden. F.G. 2016. Clinical Virology, 4th ed. Washington: ASM Press.

Schmitz, K., Barthelmes, J., Stolz, L., Beyer, S., Diehl, O., Tegeder, I. 2015. "Disease modifying nutricals" for multiple sclerosis. Pharmacology \& Therapeutics, 148, 85-113.

Seo, E.J., Fischer, N., Efferth, T. 2018. Phytochemicals as inhibitors of NF- $\kappa B$ for treatment of Alzheimer's disease. Pharmacological Research, 129, 262-273.

Singhal, T. 2020. A review of coronavirus disease-2019 (COVID-19). The Indian Journal of Pediatrics, 1-6.

Song, Z., Xu, Y., Bao, L., Zhang, L., Yu, P., Qu, Y., Zhu, H., Zhao, W., Han, Y., Qin, C. 2019. From SARS to MERS, thrusting coronaviruses into the spotlight. Viruses, 11(1), 59.

Tang, J., Luo, K., Li, Y., Chen, Q., Tang, D., Wang, D., Xiao, J. 2015. Capsaicin attenuates LPS-induced inflammatory cytokine production by upregulation of $\operatorname{LXR} \alpha$. International Immunopharmacology, 28(1), 264-269.

Thummuri, D., Jeengar, M. K., Shrivastava, S., Nemani, H., Ramavat, R. N., Chaudhari, P., Naidu, V.G.M. 2015. Thymoquinone prevents RANKL-induced osteoclastogenesis activation and osteolysis in an in vivo model of inflammation by suppressing NF-KB and MAPK Signalling. Pharmacological Research, 99, 63-73.

Toujani, M.M., Rittà, M., Civra, A., Genovese, S., Epifano, F., Ghram, A., Limbo, D., Donalisio, M. 2018. Inhibition of HSV-2 infection by pure compounds from Thymus capitatus extract in vitro. Phytotherapy Research, 32(8), 1555-1563.

Tragoolpua, Y., Jatisatienr, A. 2007. Anti-herpes simplex virus activities of Eugenia caryophyllus (Spreng.) Bullock \& SG Harrison and essential oil, eugenol. Phytotherapy Research: An International Journal Devoted to Pharmacological and Toxicological Evaluation of Natural Product Derivatives, 21(12), 1153-1158.

Tzeng, T.F., Liou, S.S., Chang, C.J., Liu, I.M. 2015. 6-gingerol protects against nutritional steatohepatitis by regulating key genes related to inflammation and lipid metabolism. Nutrients, 7(2), 999-1020.

Umar, S., Shah, M.A.A., Munir, M.T., Yaqoob, M., Fiaz, M., Anjum, S., Kaboudi, K., Bouzouaia, M., Younus, M., Nisa, Q., Iqbal, M. 2016. Synergistic effects of thymoquinone and curcumin on immune response and anti-viral activity against avian influenza virus (H9N2) in turkeys. Poultry Science, 95(7), 1513-1520.

Xu, J., Zhao, S., Teng, T., Abdalla, A.E., Zhu, W., Xie, L., Wang, Y., Guo, X. 2020. Systematic comparison of two animal-to-human transmitted human coronaviruses: SARS-CoV-2 and SARS-CoV. Viruses, 12(2), 244.

$\mathrm{Xu}$, Y., Liu, L. 2017. Curcumin alleviates macrophage activation and lung inflammation induced by influenza virus infection through inhibiting the NF- $\kappa \mathrm{B}$ signaling pathway. Influenza and Other Respiratory Viruses, 11(5), 457-463.

Wang, Y.J., Pan, K.L., Hsieh, T.C., Chang, T.Y., Lin, W.H., Hsu, J.T.A. 2011. Diosgenin, a plant-derived sapogenin, exhibits antiviral activity in vitro against hepatitis $\mathrm{C}$ virus. Journal of Natural Products, 74(4), 580-584.

Wang, B., Zhang, G., Yang, M., Liu, N., Li, Y.X., Ma, H., Ma, L., Sun, T., Tan, H., Yu, J. 2018. Neuroprotective effect of anethole against neuropathic pain induced by chronic 
constriction injury of the sciatic nerve in mice. Neurochemical Research, 43(12), 24042422.

World Health Organization (WHO). 2020a. Archived: WHO Timeline - COVID-19. https://www.who.int/news-room/detail/27-04-2020-who-timeline---covid-19 accessed on May 15, 2020.

World Health Organization (WHO). 2020b. Coronavirus disease (COVID-19) Weekly Epidemiological Update and Weekly Operational Update https://www.who.int/emergencies/diseases/novel-coronavirus-2019/situation-reports accessed on May 15, 2020.

Yahfoufi, N., Alsadi, N., Jambi, M., Matar, C. 2018. The immunomodulatory and antiinflammatory role of polyphenols. Nutrients, 10(11), 1618.

Yang, P., Wang, X. 2020. COVID-19: a new challenge for human beings. Cellular \& Molecular Immunology, 17(5), 555-557.

Yu, J.S., Chen, W.C., Tseng, C.K., Lin, C.K., Hsu, Y.C., Chen, Y.H., Lee, J.C. 2016. Sulforaphane suppresses hepatitis $\mathrm{C}$ virus replication by up-regulating heme oxygenase1 expression through PI3K/Nrf2 pathway. PLoS One, 11(3), e0152236.

Yu, Y.B., Miyashiro, H., Nakamura, N., Hattori, M., Park, J.C. 2007. Effects of triterpenoids and flavonoids isolated from Alnus firma on HIV-1 viral enzymes. Archives of Pharmacal Research, 30(7), 820.

Zhai, W.J., Zhang, Z.B., Xu, N.N., Guo, Y.F., Qiu, C., Li, C.Y., Deng, G.Z., Guo, M.Y. 2016. Piperine plays an anti-inflammatory role in Staphylococcus aureus endometritis by inhibiting activation of NF- $\mathrm{BB}$ and MAPK pathways in mice. Evidence-Based Complementary and Alternative Medicine, 2016, 8597208.

Zhang, X.X., Wu, Q.F., Yan, Y.L., Zhang, F.L. 2018. Inhibitory effects and related molecular mechanisms of total flavonoids in Mosla chinensis maxim against H1N1 influenza virus. Inflammation Research, 67(2), 179-189.

Zhang, H., Bai, Y., Gao, M., Zhang, J., Dong, G., Yan, F., Ma, Q., Fu, X., Zhang, Q., Li, C., Shi, H. 2019. Hepatoprotective effect of capsaicin against concanavalin A-induced hepatic injury via inhibiting oxidative stress and inflammation. American Journal of Translational Research, 11(5), 3029-3038.

Zheng, Q., Sun, W., Qu, M. 2018. Anti-neuro-inflammatory effects of the bioactive compound capsaicin through the NF- $\mathrm{B}$ signaling pathway in LPS-stimulated BV2 microglial cells. Pharmacognosy Magazine, 14(58), 489-494. 